\title{
ANALYSIS OF THE POVERTY STATUS OF CASHEW FARMERS IN KOGI STATE, NIGERIA
}

\author{
${ }^{*}$ Pelemo, J.J., ${ }^{2 M o h a m m e d, ~ U ., ~}{ }^{3}$ Omaku, M., ${ }^{1}$ Opara, S., ${ }^{4}$ Nnachukwu, V.C \\ 1Department of Agricultural Extension and Rural Development, Federal University of Technology Minna. \\ 2Department of Planning, Research and Statistics, Niger State Ministry of Agriculture, Minna \\ ${ }^{3}$ Department of Agricultural Education, College of Education Akwanga, Nassarawa State \\ ${ }^{4}$ Department of Agricultural Economics and Farm Management, Federal University of Technology Minna.
}

*Corresponding Author: jacobjide1986@gmail.com

\begin{abstract}
The study examined the poverty status of cashew farmers in Kogi State, Nigeria. A sample size of 210 cashew farmers was selected using the Yamane formula. Structured interview schedule was used for data collection. Data were analyzed using descriptive statistics and Foster Greer Thobecke model. The findings revealed that $94.3 \%$ of the cashew farmers were of the male gender. The mean age of cashew farmers was 54.6 years. The mean years spent in formal education among cashew farmers was seven years while the mean farm size of cashew farmers was 6.1 hectares. The average income of cashew farmers over a period of 12 months was A134,517.14 while the poverty line was $A 89,678.09$. The FGT poverty measure showed that $24.8 \%$ of cashew farmers were living below poverty line. The poverty depth was $23.14 \%$ while poverty severity was $8.7 \%$. The major constraints faced by cashew farmers were poor storage facilities and inadequate capital. It is recommended that government should provide storage and processing facilities in order to minimize the loss encountered by cashew farmers. Good and accessible feeder roads should be constructed for farmers and relevant extension sevices on cashew production should be provided to increase cashew output
\end{abstract}

Keywords: Poverty, Cashew, Farmers, Constraints 


\section{INTRODUCTION}

Poverty is a common menace affecting more than $70 \%$ of farming populace in Nigeria (Emefesi \& Yusuf, 2014). Azeez et al., (2015) reported that the majority of farming populace in Nigeria lives below the poverty line with inadequate social services and other rural infrastructures. Cashew production has been a major tool in alleviating poverty among the rural farmers (Agbongiarhuoyi et al., 2008). Food and Agricultural Organization, FAO (2012) stated that Nigeria supply one of the cheapest raw cashew nuts to Asian market with an estimated value of more than US\$ 46 million annually. FAOSTAT (2013) reported that Nigeria is the second largest producer of cashew nuts of more than 950,000 tonnes per annum after Vietnam which produces 1,110,800 tonnes. This contradicts FAO estimation of more than 180,000 tonnes produced annually. This difference may be due to inadequate documentation and improper recording among Nigeria cashew producers. However, the incentive to add value through increasing the quality supply is low with Nigerian raw nuts prices discounted in the world market (20\%-30\%) compared to those of neighbouring countries. As in the case of other developing countries, Nigeria has recognized the potential economic value of cashew and has made a concerted effort to improve production and the breed of the crop (Hammed et al., 2007). In Nigeria, cashew provides food, income and alleviation of rural poverty for the populace (Agbongiarhuoyi et al., 2008). However, inability of farmers' to increase their cashew output has resulted in the loss of most of these advantages embedded in cashew production hence making it difficult for farmers to escape poverty. However, it is very vital to increase the prospect of cashew in order to find lasting solution to the problem of poverty among farming populace. The work therefore examines poverty status of cashew farmers' in Kogi State, Nigeria. The specific objectives were to: describe the socio-economic characteristics of cashew producers; determine the poverty status of cashew farmers; and identify the constraints to cashew production.

\section{METHODOLOGY}

\section{Study Area}

The study was carried out in Kogi State Nigeria. The state was created in August, 1991 out of Kwara and Benue States. Kogi state is situated in the Guinea savannah ecological zone of Nigeria. It is located between latitude 6033' and 8044' $\mathrm{N}$ and longitude $5^{\circ} 22^{\prime}$ and $7049^{\prime} \mathrm{E}$. It shares common boundaries with Niger, Plateau, Nasarawa States and Federal Capital Territory (FCT) to the North and Benue State to the East. To the west, it is bounded by Kwara, Ondo and Ekiti state and to the South by Enugu, Anambra and Edo States. The headquarters of the State is Lokoja, which is situated at the confluence of River Niger and River Benue making the state to be popularly known as the Confluence State. The State like any other State in the country has three senatorial districts (Western, Central and Eastern senatorial districts). The state is made up of 21 
Local Government Areas (LGAs). The population of Kogi State was estimated at 3,278,487 people with land area of about 30,354.74 square kilometers (Kogi State Ministry of Information, 2015).

The State has about 2 million hectares of cultivable land with only about 0.5 million hectares currently under cultivation and well-endowed with river valleys and swamplands for dry season farming. Tree crops grown in the state, in order of comparative advantages, are cashew, oil palm, citrus, cocoa, coffee and kolanut. Also, cattle, sheep, goats and poultry are the major animals reared (Kogi State Ministry of Information, 2015). As regards cashew production in the state, the three local governments that are prominent for are ljumu, Kabba Bunu, and Yagba East. The cashew farmers are registered in groups with the state ministry of agriculture.

\section{Sampling Procedure and Sample Size}

The population for this study was made up of all registered cashew farmers in the state. For this study, the list of registered farmers in the three LGAs with preponderance for cashew production were used. A random selection of 210 farmers was made from the 443 registered farmers in nine villages using Yamane formula (1973).

The Yamane formula is expressed as;

$n=\frac{N}{1+N(\Theta)^{2}}$

Where;

$\mathrm{n}=$ sample size

$\mathrm{N}=$ finite population

$\mathrm{e}=$ limit of tolerable error $(0.05)$

Table 1 shows the determination of the sample size.

Table 1: Determination of the sample size

\begin{tabular}{|c|c|c|c|c|}
\hline & LGAs & Villages & Sampling frame & Sample size \\
\hline \multirow{3}{*}{\multicolumn{2}{|c|}{ ljumu }} & Ekinrin ade & 41 & 19 \\
\hline & & lyamoye & 45 & 22 \\
\hline & & lyara & 50 & 24 \\
\hline \multirow{3}{*}{\multicolumn{2}{|c|}{ Kabba-bunu }} & lluke & 63 & 30 \\
\hline & & Ike-bunu & 40 & 19 \\
\hline & & Okebukun & 51 & 24 \\
\hline \multirow[b]{4}{*}{ Tatal } & Yagba East & Ejuku & 43 & 20 \\
\hline & & Itakete & 60 & 28 \\
\hline & & ljowa & 50 & 24 \\
\hline & 3 & 9 & 443 & 210 \\
\hline
\end{tabular}

Source: Field Survey, 2015. 
Data were collected on the socioeconomic characteristics of the cashew farmers, poverty status, and constraints faced in production. Data were collected by the reseachers and trained enumerators using interview schedule administered by personal interview

Descriptive statistics which comprises percentages, means and frequency counts was used to achieve the first objective (socio-economic characteristic) and third objective (constraints to cashew production). The second objective (poverty status of cashew producers) was achieved using Foster-Greer-Thorbecke (1984) decomposition of poverty. This determined the poverty status of respondents in the area. This FGT weighted poverty measure was used to obtain the incidence, depth and severity of poverty.

The FGT measure for the $i^{\text {th }}$ sub-group (Pai) is given as:

$P_{a i}=\frac{1}{n} \sum_{i-1}^{q}[(z-y) / z]^{a}$

Where $\mathrm{a}=0, \mathrm{P}_{0}=\frac{1}{n} \sum_{i-1}^{q}[(z-y) / z]^{0}=\frac{\mathrm{q}}{n} \rightarrow$ Poverty incidence or head count

Where $\mathrm{a}=1, \mathrm{P}_{1}=\frac{1}{n} \sum_{i-1}^{q}[(z-y) / z]^{1} \rightarrow$ Poverty deph

Where $\mathrm{a}=2, \mathrm{P}_{2}=\frac{1}{n} \sum_{i-1}^{q}[(z-y) / z]^{2} \rightarrow$ Poverty severity

Where

$\mathrm{a}=$ degree of poverty aversion

$\mathrm{n}=$ number of households in a group

$q=$ the number of poor households

$z=$ poverty line

$y$ the per capita income $(\mathrm{PCl})$ of the ith household.

Total per-capital income TPCI = Summation of PCI

Mean TPCI = TPCI/ Total number of household

Poverty line $P L=\frac{2}{3} \times$ MTPC 


\section{RESULTS AND DISCUSSION}

\section{Socio-economic Characteristics of Cashew Producers}

Table 2 shows the results of socio-economic characteristics of cashew producers. Table 2 indicates that $94.3 \%$ of cashew producers were male while $5.7 \%$ of the respondents were female. This indicates that more males are engaged in cashew production than females in the study area. This might be as a result of involvement of women in post-harvest and other activities. This finding agrees with that of Rashid et al. (2015), who found out that more men were dominant in agricultural activities than women in Nigeria. Table 2 reveals that cashew producers had mean age of 54.6 years. This shows that cashew production in the state is carried out by elderly people. This finding is in line with that of Agbongiarhuoyi et al. (2008) who reported that production of cashew in Kogi State, Nigeria is mostly done by aged people. The mean years spent in formal education among cashew producers in Table 2 was seven years. This result suggests that most of the respondents had low literacy level. This development is unhealthy for cashew production in the state because this could have a negative effects on the poverty status of cashew producers. Table 2 shows that the mean farm size of cashew producers was 6.1 hectares. This is an indication that most of cashew producers in Kogi State operate on medium scale. This is in line with that of Aliber and Hart (2015), who reported most rural farmers in Sub-Saharan Africa cultivate on medium scale. Table 2 shows the mean annual income of cashew producers was A134,517.1 per annum. The income distribution of the respondents suggest that the cashew producers in the study area were low income earners. 
Table 2: Socio-economic characteristics of cashew farmers

\begin{tabular}{|c|c|c|c|}
\hline Variables & Frequency & Percentages & Mean \\
\hline \multicolumn{4}{|l|}{ Gender } \\
\hline Male & 198 & 94.3 & \\
\hline Female & 12 & 5.7 & \\
\hline \multicolumn{4}{|l|}{ Age } \\
\hline$\leq 40$ & 12 & 5.7 & 54.6 \\
\hline$\overline{4} 1-50$ & 66 & 31.4 & \\
\hline $51-60$ & 86 & 41.0 & \\
\hline$>60$ & 46 & 21.9 & \\
\hline$>40$ & 19 & 13.6 & \\
\hline \multicolumn{4}{|c|}{ Years spent in school } \\
\hline None & 72 & 34.3 & 7.0 \\
\hline $1-6$ & 86 & 41.0 & \\
\hline $7-12$ & 24 & 11.4 & \\
\hline $13-18$ & 28 & 13.3 & \\
\hline \multicolumn{4}{|l|}{ Farming size } \\
\hline $1-5$ & 99 & 47.1 & 6.1 \\
\hline $6-10$ & 99 & 47.1 & \\
\hline $11-15$ & 4 & 1.9 & \\
\hline $16-20$ & 7 & 3.3 & \\
\hline$>20$ & 1 & 0.5 & \\
\hline \multicolumn{4}{|l|}{ Annual income } \\
\hline $1-50,000$ & 13 & 6.2 & A134,517.1 \\
\hline $51,000-100,000$ & 62 & 29.5 & \\
\hline $101,000-150,000$ & 69 & 32.9 & \\
\hline $151,000-200,000$ & 43 & 20.5 & \\
\hline$>200,000$ & 23 & 11.0 & \\
\hline \multicolumn{4}{|l|}{ Extension access } \\
\hline Yes & 107 & 51.0 & \\
\hline No & 103 & 49.0 & \\
\hline \multicolumn{4}{|l|}{ Credit access } \\
\hline Yes & 101 & 48.1 & \\
\hline No & 109 & 51.9 & \\
\hline
\end{tabular}

Sources: Field survey, 2015

Table 2 further shows that $51.0 \%$ of the respondents had access to extension services while $49.0 \%$ did not. Access to extension service in the context of agricultural technology is expected to influence adoption. Yaron et al. (1992) reported that extension plays an important role in neutralizing the problems that arise from inadequate formal education. Table 2 shows that $48.1 \%$ of farmers accessed credit. However, this development could negatively affect the poverty status of cashew producers in the study area owing to the fact that credit is need to enhance the poverty status of cashew farmers. 


\section{Poverty Status of Cashew Producers}

Table 3 shows the poverty status of cashew producers in the study area. The total annual income of the respondents in the study area was A282,448,600. The average income of cashew

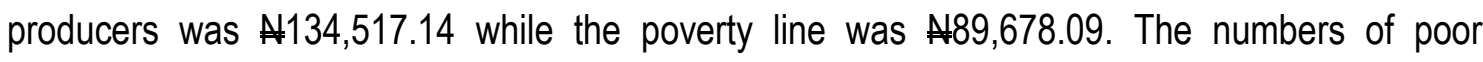
households were 52 . According to FGT the poverty measures, $24.8 \%$ of cashew farmers in the study area were living below poverty line, this shows that poverty exist slightly in the study area. The poverty depth was 0.2314 , indicating that $23.14 \%$ increase in income is required by the poor farmers to escape from poverty. In addition, the severity of poverty was 0.0872 . This implies that about $8.72 \%$ of cashew farmers were exremely poor in the study area. The poverty severity takes into account not only the distance separating the poor from the poverty line, but also the inequality among the poor.

Table 3: Distribution of cashew producers according to poverty status

\begin{tabular}{lcl} 
Poverty status & Frequency & Percentage $\%$ \\
\hline Poor & 52 & 24.8 \\
Non poor & 158 & 75.2 \\
Total & 210 & 100 \\
FGT indices & Head count index & Poverty depth Poverty severity \\
Value & 0.248 & 0.23140 .0872 \\
Poverty line $=\frac{2}{3} \times$ N134,517.1429 $=$ A89,678.09 & & \\
\hline
\end{tabular}

\section{Sources: Field survey, 2015}

\section{Constraints to Cashew Production}

Table 4 reveals the results of the constraints to cashew production in the study area. The table shows that the most important constraint to cashew production in the study area was lack of processing facilities. This is followed by lack of storage facilities. This constraint is well pronouced in Nigeria compared to other advanced countries that makes use of cashew apple. This finding agrees with Oladejo (2015), who reported that lack of processing and storage facilities were the major constraints affecting cashew production in Nigeria. Akinwale and Ayodele (1999) also reported that despite the increase in cashew production in Nigeria, only the cashew nuts are presently being utilized in the processing industry whereas the cashew apple wastes away. Inadequate capital and lack of good road rank 3rd and 4th respectively. This finding is in consonance with Oladejo (2015), who stated that inadequate capital and lack of good roads were some of the major problems faced by cashew marketers in Nigeria. Other constraints affecting cashew production in the study area were high cost of transport ranked 5th, insufficient price information ranked 6th, poor quality of nut ranked 7 th, inadequate extension ranked 8th, 
insufficient buyers ranked 9th and insufficient labour ranked 10 th. Agbongiarhuoyi et al. (2008) reported that insufficient price information, poor quality of nuts and inadequate extension on cashew production were the major constraints faced by cashew producers in Kogi State.

\section{Table 4: Constraints to cashew production}

\begin{tabular}{lll}
\hline Variables & Frequency & Percentages \\
\hline Inadequate extension & 90 & 42.9 \\
Inadequate capital & 202 & 96.2 \\
Insufficient price information & 180 & 85.7 \\
Lack of processing facilities & 208 & 99.0 \\
High cost of transport & 169 & 80.5 \\
Lack of good road & 190 & 90.5 \\
Insufficient labour & 48 & 22.8 \\
Lack of storage facilities & 205 & 97.6 \\
Poor quality of nuts & 107 & 50.9 \\
Insufficient buyers & 53 & 25.2 \\
\hline
\end{tabular}

\section{Sources: Field survey, 2015}

\section{CONCLUSION}

Cashew production was male dominated in the study area. Cashew production in the study area was found to be predominated by elderly males with limited formal education. Also, cashew producers are low income earners and this is expected to affect their poverty status. Poverty status analysis revealed that less than one quarter of the respondents were poor. Also, inadequate processing, poor storage facilities and inadequate capital were some of the constraints affecting cashew production in the study area.

Therefore, it is recommended that adequate capital and other production incentives be provided for farmers in order to maximise their production and improve their poverty status. Government should provide storage and processing facilities in order to minimize the loss encountered by the farmers. Good and accessible feeder roads should be constructed for farmers so as to reduce the cost of transportation of cashew nuts from farm to village markets. Besides, relevant extension sevices on cashew production should be provided to increase cashew output and alleviate poverty. 


\section{REFERENCES}

Agbongiarhuoyi, A.E., Aigbekaen, E.O. and Akinbile, L.A. (2008). Awareness of cashew products potentials and market information among farmers in Kogi State, Nigeria. ARPN Journal of Agricultural and biological Science, 3(4), 10-15.

Akinwale, T.O. and Ayodele, E.A. (1999). Economic importance of cashew. Quarterly Nigeria's First Magazine Journal, 2(9), 45-47.

Aliber, M., and Hart, T.G.B (2015). Should subsistence agriculture be supported as a strategy to address rural food security? Agrecon, 48 (4), 434-456.

Azeez, A., Ademola S., and Abang, O. (2015). Analysis of Poverty Status of Rural Farm Families in Akwa Ibom State Nigeria. Global Journal of Agricultural Science, 14 (1), 45-50.

Emefesi, B.O., and Yusuf, B. (2014). Access and Impact of micro credit on poverty alleviation among farmers in Kirfi local Government Area of Bauchi State. Journal of Agriculture and Veterinary Science, 11 (1), 30-35.

Food and Agriculture Organization (2012). Cashew production in Africa, 1990-2000. Food and Agricultural Organisation of the United Nation. Production database. Retrieved on September 10, 2014 from http:apps.fao.org/page/collection.

FOASTAT, (2013). Food and Agriculture Organization Statistics. Pp. 1-125

Foster, J., Greer, J. and Thorbecke, E. (1984). A Class of Decomposable Poverty Measures. Econometrica, 52(3), 761-766.

Hammed, L.A., Adedeji, A.R., Asogwa, E.U. and Ibiremo, O. (2007). Constraints to Cashew Production in Nigeria, A paper presented at the cashew stake-holders meeting organized by the African Cashew Alliance (ACA) held at IITA Ibadan, Nigeria. Pp.12.

Kogi State Ministry of Information (2015). Working Document. Pp 1-54

Oladejo, J.A. (2015). Profitability and Structural analysis of cashew nut market in Oyo State, Nigeria. International Journal of Agricultural Policy and Research, 3 (3), 114-121.

Adisa, R.S., Adefalu, L.L., Olatinwo, L.K., Balogun, K.S., and Ogunmadeko, $O .0$ (2015). Determination of Post-harvest Losses of Yam among Farmers in Ekiti State, Nigeria. Bulletin of the Institute of Tropical Agriculture, Kyushu University, 38(1), 73-78. 
Yaron, D., Dinar, A. and Voet, H. (1992). Innovations on Family farms: The Nazareth Region in Israel. American Journal of Agricultural Economics, 74(2), 361-370. 